\title{
Ultrasound-guided Diagnostic and Therapeutic Approach to Retrocalcaneal Bursitis
}

ANGEL CHECA, MD; WILLIAM CHUN, MD; RAMESH PAPPU, MD, Division of Rheumatology, Drexel University College of Medicine, 219 North Broad Street, 9th Floor, Philadelphia, Pennsylvania 19107, USA. Address correspondence to Dr. A. Checa; E-mail: checaag@comcast.net.

J Rheumatol 2011;391-2; doi:10.3899/jrheum.100920

The anatomy, physiology, and pathophysiology of the retrocalcaneal bursa $(\mathrm{RB})$ have been described well ${ }^{1,2}$. Ultrasound has been shown to be a valuable tool by enhancing the accuracy of challenging procedures that in the past have

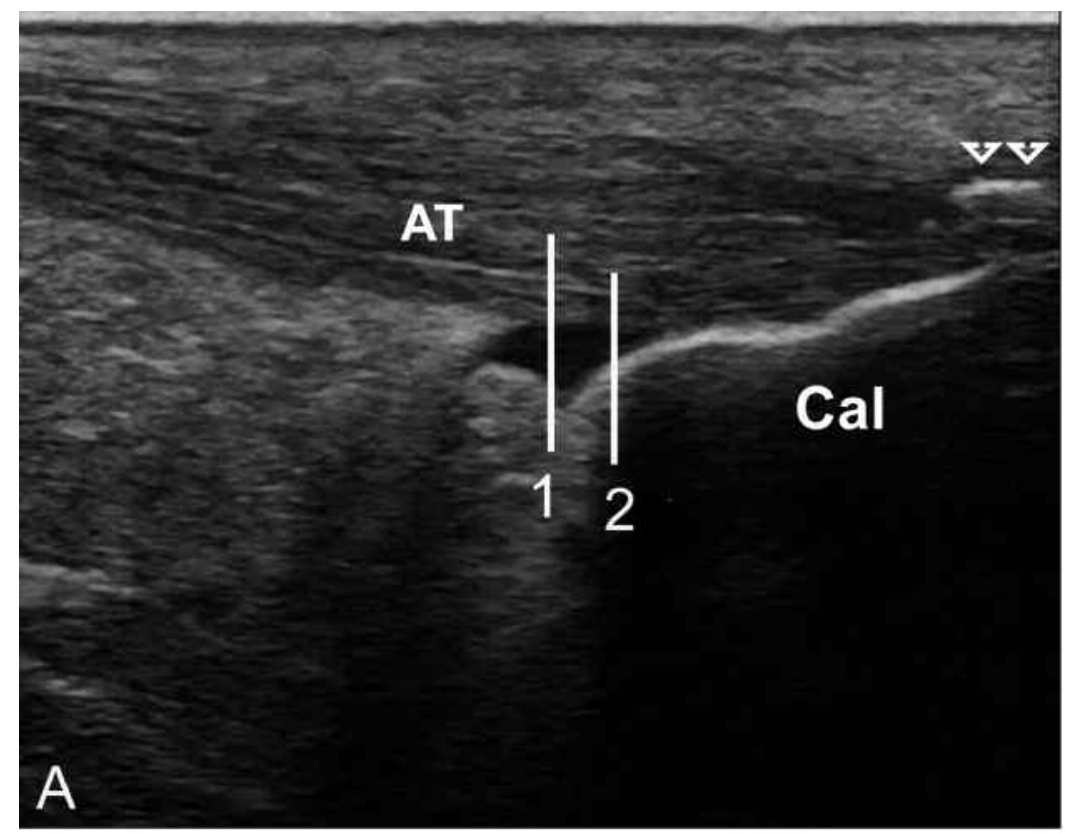

Figure 1. Longitudinal sonographic view (A) of the sub-Achilles area showing a triangular anechoic area between the Achilles tendon (AT) and the calcaneus (Cal), consistent with retrocalcaneal bursitis. Arrowheads indicate a calcaneal spur. B. Transverse view shows retrocalcaneal bursa (RB) at level 1 of view A. C. Transverse view shows RB at level 2 of view A. wedged between the Achilles tendon and the calcaneus consistent with retrocalcaneal bursitis. A hyperechoic band (Figure 1A, arrowheads) showed a calcaneal spur. Transverse views (Figures $1 \mathrm{~B}$ and $1 \mathrm{C}$ ) illustrate RB at 2
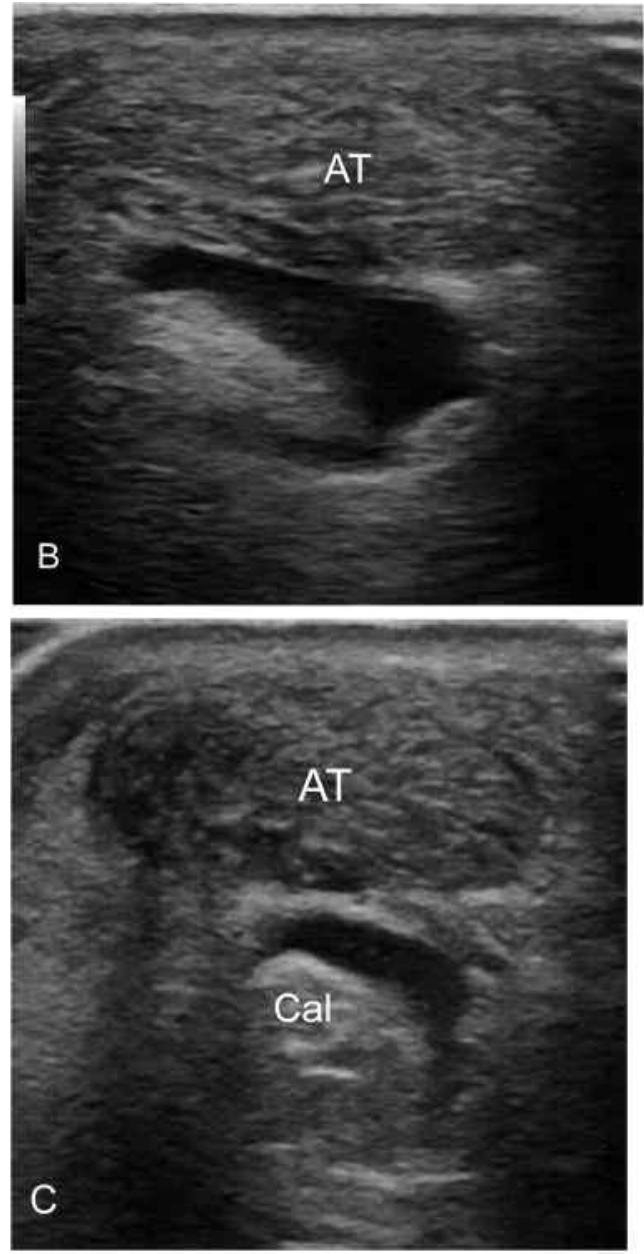

been performed blindly, such as aspiration or injection of the $\mathrm{RB}^{3,4}$. We describe ultrasound-assisted corticosteroid injection of this structure.

A 55-year-old woman with osteoarthritis presented with left heel pain. On examination she had swelling and tenderness in the left retrocalcaneal area. The ankle joint was unremarkable. A longitudinal sonographic view of the subAchilles area (Figure 1A) showed a triangular anechoic area levels (indicated as 1 and 2 of longitudinal view, Figure 1A). A sonographic-assisted injection of $10 \mathrm{mg}$ triamcinolone acetonide was performed in the RB using a lateral approach (Figure 2A). Figures 2B, 2C, and 2D show needle placement (indicated as $*$ ) and medication passage into the bursa. No complications of the procedure ensued and the patient's bursitis had resolved by the time she returned for a 2-month interval visit. 
Ultrasound guidance enhances the accuracy of injection of the retrocalcaneal bursa. The Achilles tendon and retrocalcaneal bursa are easily distinguished sonographically and the needle can be guided into the bursa under direct visualization while avoiding the tendon.

\section{REFERENCES}

1. Canoso J, Liu N, Trail MR, Runge VM. Physiology of the retrocalcaneal bursa. Ann Rheum Dis 1988;47:910-2.
2. Kachlik D, Baca V, Cepelik M, Hajek P, Mandys V, Musil V, et al. Clinical anatomy of the retrocalcaneal bursa. Surg Radiol Anat 2008;30:347-53.

3. Cunnane G, Brophy DP, Gibney RG, FitzGerald O. Diagnosis and treatment of the heel pain in chronic inflammatory arthritis using ultrasound. Semin Arthritis Rheum 1996;25:383-9.

4. Balint PV, Sturrock RD. Inflamed retrocalcaneal bursa and Achilles tendonitis in psoriatic arthritis demonstrated by ultrasonography. Ann Rheum Dis 2000;59:931-3.
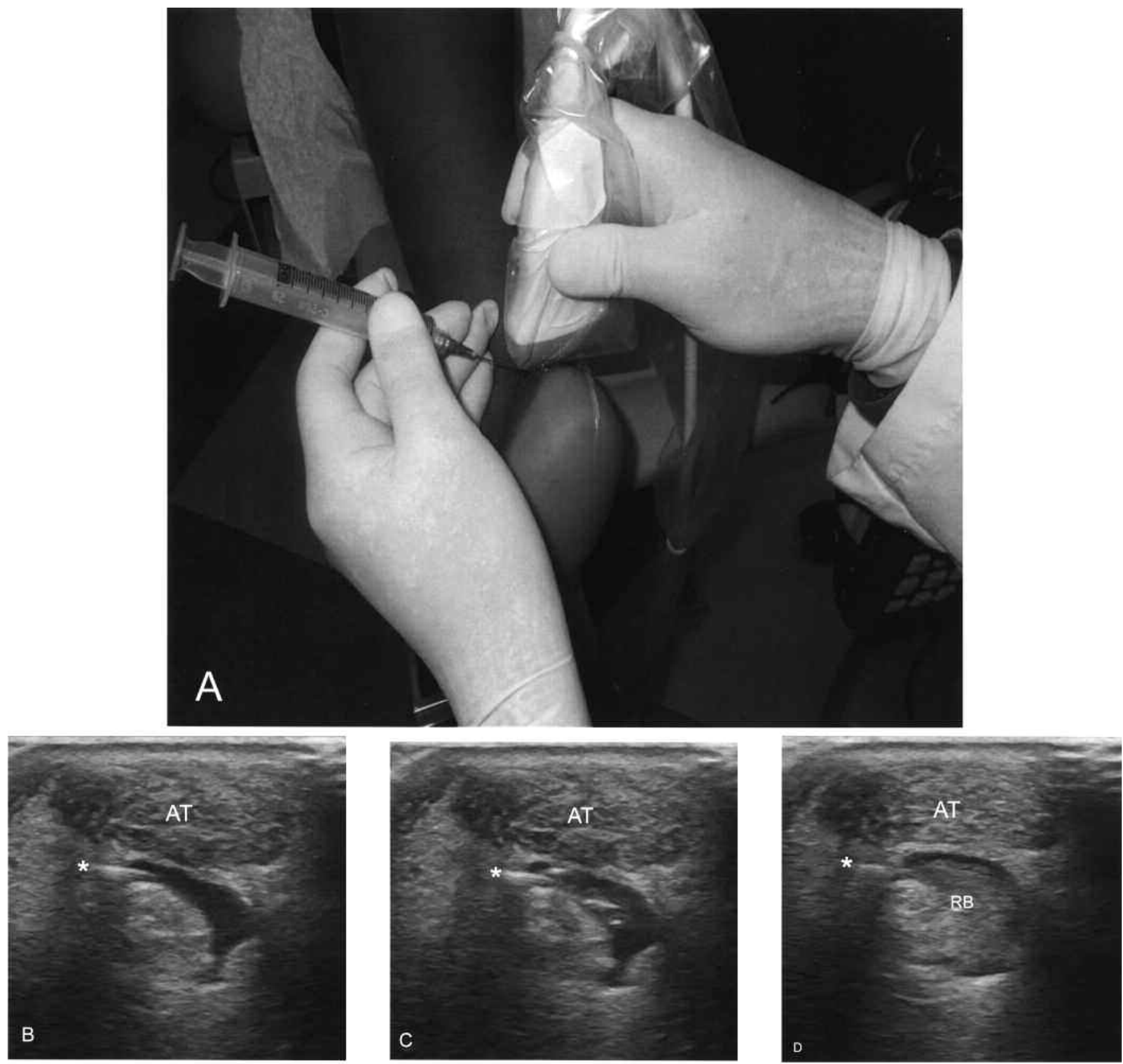

Figure 2. A. Injection of $10 \mathrm{mg}$ triamcinolone acetonide into the retrocalcaneal bursa was sonograph-assisted using a lateral approach. B, C, D. Needle placement $(*)$ and medication passage into the bursa. 